\title{
Bacteriological and Molecular Assessment of Staphylococcal Enterotoxin E in the Blood of Patients With Rheumatoid Arthritis
}

\author{
Samaneh Zahiri Yeganeh ${ }^{1}$; Ramezan Ali Ataee $^{2,}$; Gholam Hossein Alishiri ${ }^{3}$; Monireh Movahedi ${ }^{1}$ \\ ${ }^{1}$ Department of Microbiology, Faculty of Sciences, Karaj Branch, Islamic Azad University, Karaj, IR Iran \\ ${ }^{2}$ Department of Medical Microbiology, Faculty of Medicine, Baqiyatallah University of Medical Sciences, Tehran, IR Iran \\ 3 Department of Rheumatology, Faculty of Medicine, Baqiyatallah University of Medical Sciences, Tehran, IR Iran \\ *Corresponding author: Ramezan Ali Ataee, Department of Medical Microbiology, Faculty of Medicine, Baqiyatallah University of Medical Sciences, P.O. Box: 19395-5487, Tehran, IR \\ Iran. Tel: +98-9122190418, E-mail: ataee@bmsu.ac.ir, ataee216@gmail.com
}

Received: December 5, 2013; Revised: January 27, 2014; Accepted: February 13, 2014

\begin{abstract}
Background: Rheumatoid arthritis (RA) is the most common chronic inflammatory disease of unknown etiology. In this regard, the role of bacterial superantigens (as an effective agent) were considered.

Objectives: This study aimed to assess staphylococcal enterotoxin $\mathrm{E}$ in the blood of patients with rheumatoid arthritis.

Patients and Methods: A total of 83 blood samples of patients with RA were studied. All of patient's blood samples have been cultured. Polymerase chain reaction(PCR) and ELISA methods have been used to assess the existence of staphylococcal enterotoxin $\mathrm{E}$ (entE). The data were analyzed through descriptive statistics.

Results: During this study and after sequential sub cultures, only 5 bacterial strains were isolated. Based on the results of biochemical tests, just one case was detected as Staphylococcus aureus. The result of molecular diagnosis of enterotoxin E gene was $13.25 \%$. The results of ELISA were $40.96 \%$ positive for staphylococcal enterotoxin $\mathrm{E}$.

Conclusions: In this study, staphylococcal enterotoxin E (superantigen E) was detected in the blood of patients with RA, but its origin is unknown, because no staphylococcus enterotoxin E producer was isolated. This finding could provide a good model for the diagnosis and treatment of RA. However, the results of this study have shown some evidence regarding endogenous origin of involved superantigens in patients with rheumatoid arthritis.
\end{abstract}

Keywords: Rheumatoid Arthritis; Staphylococcus aureus; Superantigen; Polymerase Chain Reaction; Enzyme-Linked Immunosorbent Assay

\section{Background}

Staphylococcus aureus has different virulence factors such as enterotoxins that could act as superantigens. These superantigens could stimulate $\mathrm{T}$ lymphocytes and trigger a cytokine storm (1). In addition, these enterotoxins are among the most common causes of food poisoning $(2,3)$ as well as chronic diseases $(4,5)$ such as septic shock and arthritis (6). However, antibiotic resistance and production of toxins have made $S$. aureus an opportunistic pathogen (7).

One of the most important enterotoxins that are produced by $S$. aureus is staphylococcus enterotoxin E (SEE) (8). This superantigen is one of the classical superantigens, which has the most similarity with staphylococcal enterotoxin A (SEA), and the lowest prevalence among others (9). Some reports stated that $84 \%$ similarity exists between SEE, SEA, and staphylococcal enterotoxin P (SEP) with respect to their genome sequences (10). The existence of S. aureus enterotoxins in patient's blood has not been considered. However, in the case of septic arthritis, staphylococcal species strain with antibiotic resistance were isolated from synovial fluid of rheumatoid arthritis (RA) patients (11).

Recent studies were shown that the molecular fingerprinting of a collection of 94 S. aureus isolates from patients with osteomyelitis and methicillin-resistant was significantly higher among others that were not resistant (12). The results of another study showed that superantigens as virulence factors are effective in staphylococcal infections (13). The role of staphylococcal superantigens as virulence factors in some chronic diseases such as RA and nonseptic arthritis has been reported (6). Thus, the purpose of this study was to assay the staphylococcal enterotoxin E in RA patients' blood.

\section{Objectives}

This study aimed to assess staphylococcal enterotoxin $\mathrm{E}$ in the blood of patients with rheumatoid arthritis.

\section{Patients and Methods}

S. aureus strain, which contained the entE gene and pro-

Copyright (c) 2015, Ahvaz Jundishapur University of Medical Sciences. This is an open-access article distributed under the terms of the Creative Commons Attribution-NonCommercial 4.0 International License (http://creativecommons.org/licenses/by-nc/4.0/) which permits copy and redistribute the material just in noncommercial usages, provided the original work is properly cited. 
ducing enterotoxin E isolated from the clinical samples and were characterized by Gen Bank reference (M21319.1) as the standard strain (14).

\subsection{Blood Sample Collection}

From April 2011 to August 2013, a total of 83 patients with RA were referred to laboratory by rheumatologists. Inclusion and exclusion criteria of the RA patients were based on ACR 2010 criterion (15). This project was approved by Ethics Committee of Baqiyatallah University of Medical Sciences on November 29, 2011 with Code No: 24 Paragraph 28. Sampling has been carried out based on Microbial Standard Protocol and by perfect observance of aseptic conditions. Thus, after disinfecting the sampling site, 5 to $10 \mathrm{~mL}$ blood were taken by syringe. Then, 3 - 5 $\mathrm{mL}$ of the blood was inoculated into Castaneda medium (Baharafshan Co, Tehran, Iran) and has been incubated at $37^{\circ} \mathrm{C}$ for 48 hours. Next, $2 \mathrm{~mL}$ of the collected blood has been added to sterile $\mathrm{CBC}$ tube and the remained was added to clotting tube.

\subsection{Blood Culture}

After inoculating Castaneda medium for 48 hours incubation at $37^{\circ} \mathrm{C}, 1 \mathrm{~mL}$ of Castaneda medium was aspirated and subcultured on blood agar plate (CONDA. SA). After incubation for 24 hours and at $37^{\circ} \mathrm{C}$, the isolated bacterial strains have been studied by using colony characteristics, Gram stain, catalase, oxidase, motility, sugar fermentation, DNase (Merck Germany), coagulase tests, and susceptibility to bacitracin and novobiocin.

\subsection{DNA Extraction from Bacteria}

For performing the PCR method, the bacterial standard strain was inoculated into the $5 \mathrm{~mL}$ LB broth medium (Merck Germany) for 24 hours incubation at $37^{\circ} \mathrm{C}$. The bacterial suspensions were centrifuged, and cellular sediments were obtained and then the DNA extraction has been done by using modified salting-out method (16).

\subsection{DNA Extraction From Blood}

In aseptic condition, patient's blood has been carefully added to CBC tube and was centrifuged (10 min, $7000 \times$ $\mathrm{g}$ in $\left.4^{\circ} \mathrm{C}\right)$. Then, blood buffy coat was selected and transferred to DNA free sterile tube. Next, each of the blood buffy coat genomes has been separately extracted by CinnaPure DNA Extraction Kit (Cinnagen Co. Iran). Based on the Kit instructions, the amount of $100 \mu \mathrm{L}$ of blood buffy coat has been added to the Kit's microtube, then $400 \mu \mathrm{L}$ of lysis buffer was added to it and vortexed for 20 seconds, then $300 \mu \mathrm{L}$ of precipitation solution has been added to microtube and again vortexed for 5 seconds. In this stage, all microtube components have been transferred to the column, and centrifuged $\left(1\right.$ minute, $\left.5^{\circ} \mathrm{C}, 13000 \times \mathrm{g}\right)$. Then, the column has been transferred to the new microtube and has been washed by $400 \mu \mathrm{L}$ of washing buffer 1 , and again was centrifuged $\left(1\right.$ minute, $\left.5^{\circ} \mathrm{C}, 12000 \times \mathrm{g}\right)$. Then, for the second time, the column was transferred to the other new microtube and washed by $400 \mu \mathrm{L}$ of washing buffer 2 , and again was centrifuged $\left(1\right.$ minute, $5^{\circ} \mathrm{C}, 12000$ $\times \mathrm{g}$ ). After drying and changing the column, the amount of $30 \mu \mathrm{L}$ of elution buffer was added and centrifuged (5 minutes, $12000 \times$ g), finally the DNA quality and quantity were measured by NanoDrop (Thermo Scientific NanoDrop 2000 Spectrophotometer, USA).

\subsection{Primer Design}

Using online Gene script software, the primer was designed on the basis of the reference sequence ( $S$. aureus MW2 enterotoxin E gene, access number: M21319.1) and was analyzed by primer3 software. In addition, multiple alignments were carried out by DNASIS MAX trial version. This primer pair was amplified a $693 \mathrm{bp}$ fragment.

\subsection{Polymerase Chain Reaction}

PCR method has been set up for the diagnosis of enterotoxin E gene, by using the specific primer pairs, which amplified a $693 \mathrm{bp}$ fragment and the standard strain genome. For DNA amplification, the master mix was made in $200-\mu \mathrm{L}$ microtubes using a $25 \mu \mathrm{L}$ reaction mixture that contained the $2 \mu \mathrm{L}$ DNA template, $0.3 \mathrm{U}$ of Taq DNA polymerase, $2.5 \mu \mathrm{L}$ of 10X PCR buffer as well as $0.16 \mathrm{mM}$ of each dNTPs, $2 \mathrm{mM}$ $\mathrm{MgCl} 2$ (all reagents were from Cinnagen Co, Iran), 10 pmol of the primer pair (synthesized by Cinnagen) and doubledistilled water, to a final volume of $25 \mu \mathrm{L}$. All amplifications were carried out in a thermal cycler (Bio-Rad, C1000) with initial denaturation at $95^{\circ} \mathrm{C}$ for 3 minutes followed by 35 cycles of denaturation at $94^{\circ} \mathrm{C}$ for 30 seconds, primer annealing at $61^{\circ} \mathrm{C}$ for 40 seconds and extension at $72^{\circ} \mathrm{C}$ for 40 seconds, followed by a final extension at $72^{\circ} \mathrm{C}$ for 5 minutes. The amplified PCR products have been electrophoresed in a 1.5\% agarose gel for 45 minutes, and then stained with ethidium bromide for 20 minutes $(0.05 \mathrm{mg} / \mathrm{mL}$; Sigma Aldrich). The gels were photographed under ultraviolet light using Gel Doc (Bio-Rad Universal Hood II, USA). Also, molecular size markers (50 and $100 \mathrm{bp}$ ) have been included in each agarose gel. Then, all sample buffy coat genomes have been assayed by the optimization PCR.

\subsection{Enzyme-Linked Immunosorbent Assay}

The indirect Enzyme-Linked Immunosorbent Assay (ELISA) was used for the validation of the enterotoxin E existence in patients' blood samples. First, patients' plasma (after that $\mathrm{CBC}$ tube has been centrifuged in 10 minutes with $7000 \times \mathrm{g}$ ) was taken out and assessed by ELISA with the following procedure. Based on previous report (17), $50 \mu \mathrm{L}$ of patients' plasma have been mixed with $50 \mu \mathrm{L}$ of phosphate-buffered saline as diluents. Then, they were added to the defined wells of ELISA plates that were previously coated with polyclonal monospecific antibody against staphylococcal enterotoxin E (Rb PAb staphylococcus enterotoxins E 15922500 lot 713307 Abcam). After one hour incubation and three times washing, $50 \mu \mathrm{L}$ con- 
jugate antibody was added. Then, enzyme substrate was added, and finally $100 \mu \mathrm{L}$ stopping solution was added. After 10 minutes of this process, the color changed. Finally, the wells absorption were measured by the ELISA reader device in $450 \mathrm{~nm}$ wavelength and then the cut off value has been calculated for each plates.

\section{Results}

A total of 83 blood samples were assessed patients with RA from April 2011 to August 2013. During this research and after sequential sub cultures, only 5 bacterial species were isolated. Based on the results of biochemical tests, just one case has been detected as S. aureus and others as S. intermedius, as well as three Gram negative bacterial strains: two strains as Psedumonas putida and one strain as $P$. aeroginosa.

\subsection{The Results of DNA Extraction}

The quality and quantity of the standard strain and patients sample genomes have been examined by both gel electrophoresis (the agarose gel concentration $0.8 \%$, in 100 volt for 45 minutes) and NonoDrop device. Anyhow, both results were acceptable.
4.2. The Results of Primer Design and PCR of the Blood of Patients with Rheumatoid Arthritis

The results of primer designing were as follows: F- gtagc GGATCC agc gaa gaa ata aat gaa a and R-gcgcg AAGCTT tca agt tgt gta taa ata c, which were amplified at 693 bp amplicons as PCR products. After some examinations based on the standard strain genome and Master Mix components, PCR has been set up and applied as a positive control for each test. The results of the samples' PCR with amplifier primer of a $693 \mathrm{bp}$ fragment suggested positive in 13.25\% (Figure 2). Of samples, there was a part of entE gene. Figure 2 shows the result of PCR product electrophoresis with amplifier primer of a $693 \mathrm{bp}$ fragment for a number of samples.

\subsection{The Results of Enzyme-Linked Immunosorbent Assay (ELISA)}

The results of Enzyme-Linked Immunosorbent Assay ELISA plates indicated that $40.96 \%$ of RA boold (plasma) were positive for staphylococcal enterotoxin E (Figure 3). The comparative results of PCR, ELISA, and bacterial culture were illustrated in Figure 4.

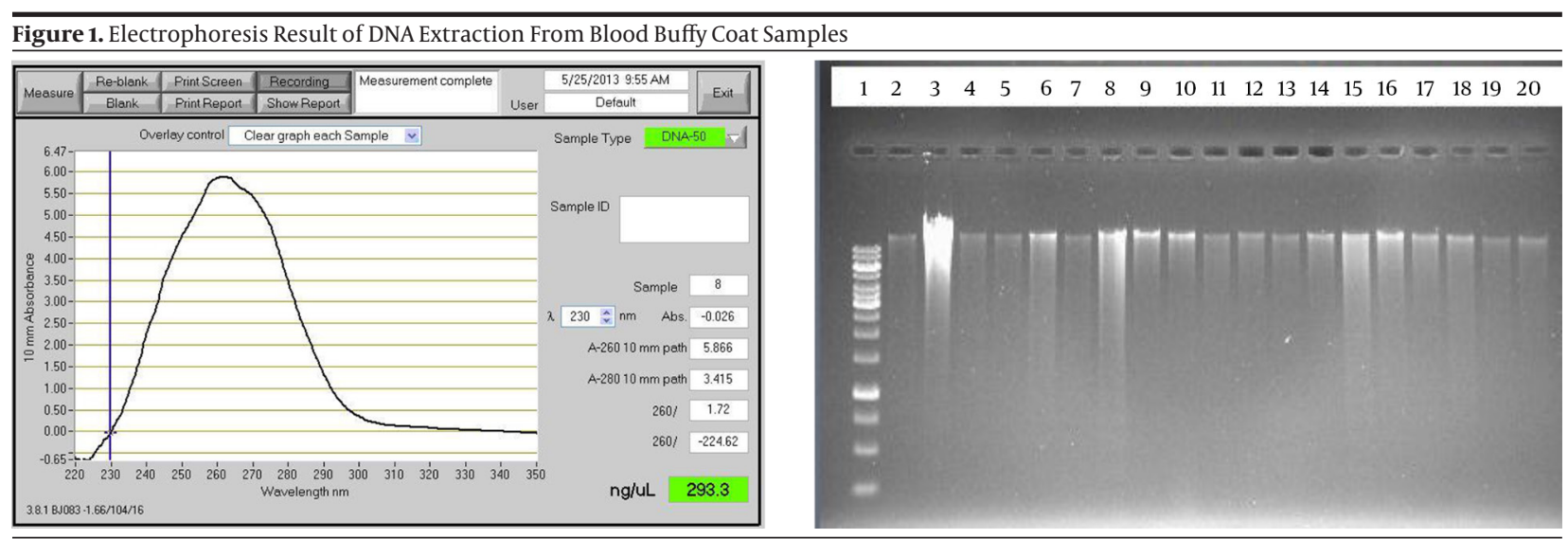

Line 1 is 100 bp molecular marker, lines 2 to 20 are DNA that has been extracted from patient's blood.

Figure 2. An Example of the Result of PCR Amplicon $693 \mathrm{bp}$

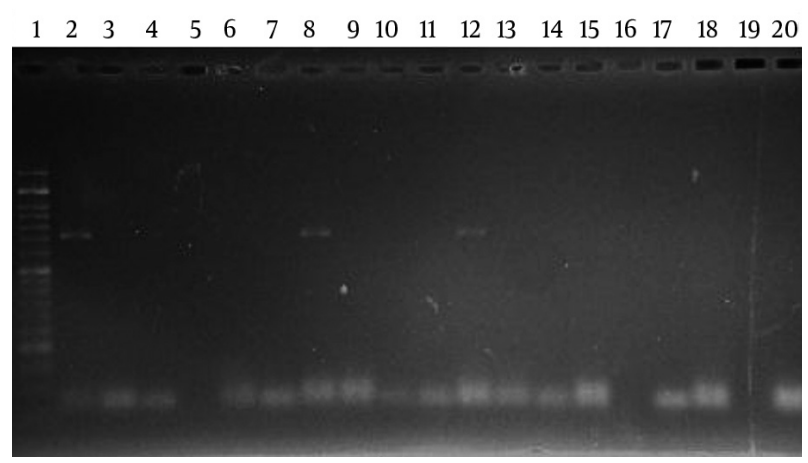

Line 1 is a 50 bp MW standard, lines 2, 8, and 12 have shown the 693 bp and line 20 is negative control.

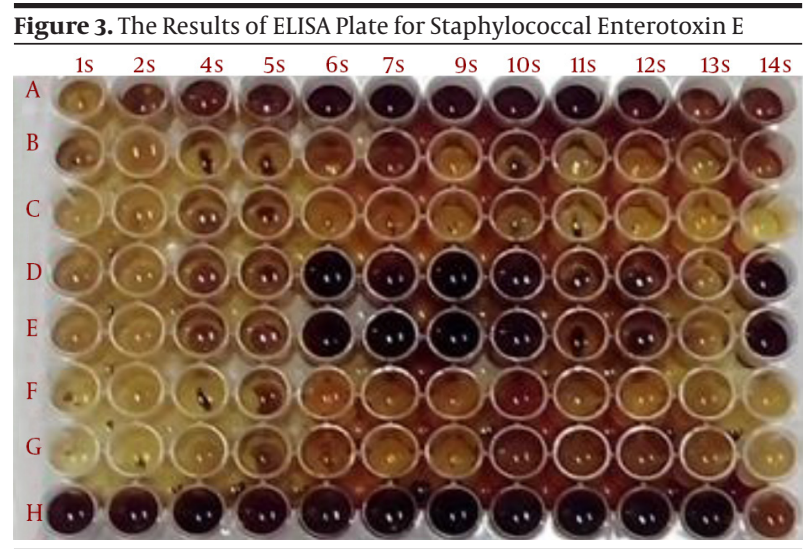

The vertical rows are patient's number and the horizontal rows are cited based on entrotoxin's names. $F$ and $G$ rows are negative controls and $H$ row is the positive control. 
Zahiri Yeganeh S et al.

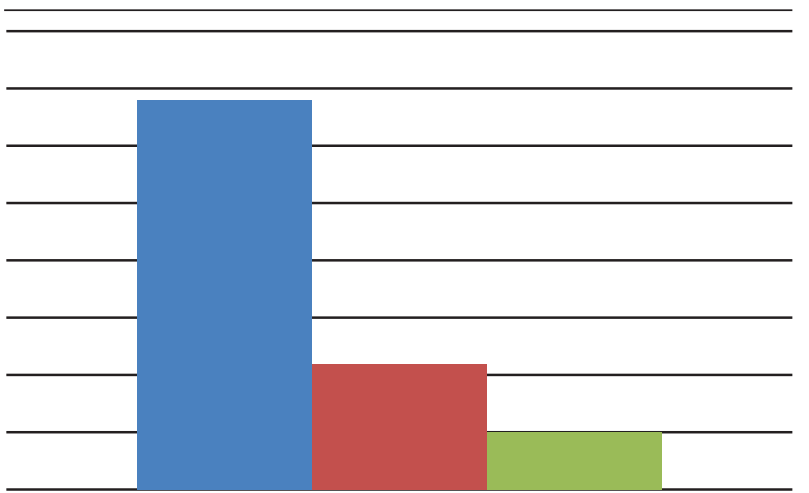

ELISA SEE in Blood

staphylococcal ent E gene in blood

the microorganism that was isolated

Figure 4. Comparative Results of Staphylococcal Enterotoxin E by PCR and ELISA with Bacterial Culture Positive Assay of 83 RA Patients' Blood Samples

\section{Discussion}

The exact etiology of RA is not determined yet; nevertheless, all scientists have recognized it as an inflammatory reaction. To clarify the disease etiology, many researches were conducted. For example, Sioud et al. designed and conducted a study on TcR V $\alpha$ in IL-2R + T cells from 6 patients, which showed restriction in their SF T cell receptor variable region $\beta$ (TcR V $\beta$ ) gene usage (18). In another study, the correlation between the inflammatory proteins such as IL-1 $\beta$; IL-6 and fibrinogen as well as Tumor Necrosis Factor alpha (TNF- $\alpha$ ) and the number of blood monocytes were demonstrated (19). An experimental model by using intravenous injection of toxic shock syndrome toxin-1 (TSST-1) provides a means to examine the possible role of superantigens in RA and related diseases, and also to analyze the cellular and molecular pathways induced by microbial products (20).

It is reported that the Mycoplasma arthritidis products, named M. arthritidis-T cell mitogen (MAM) and Mycoplasma arthritidis-derived superantigen (MAS), have biological activities in common with superantigens such as MAS, staphylococcal enterotoxin E (SEE), or lipopolysaccharide (LPS). The ability of MAM to induce proinflammatory interleukin 1 beta (IL-1 beta) and tumor necrosis factor alpha (TNF- $\alpha$ ) gene expression in the THP-1 monocytic cell line were examined and showed that play an important role in the pathology of arthritis in rodents, which closely resembles human RA (21, 22 ). The results of one investigation revealed that the level of IgM and IgG antibodies against staphylococcal enterotoxin $\mathrm{D}$ (SED) were higher compared to normal cases. The investigators concluded that stimulation of B cells using SED preferentially induced RF plus B cells in normal controls and in patients with seronegative and seropositive RA (23).

In one study, T cells were cultured with SEB in the presence of interferon- $\gamma$ (IFN- $\gamma$ )-treated synovial cells. Then, T cell proliferation and activation were assessed by $3 \mathrm{H}$-thymidine incorporation and IL-2 production and showed that activated synovial cells are potent antigen-presenting cells for SEB to T cells, and concluded that that superantigen (SEB) may play a critical role in the pathogenesis of RA through activated synovial cells (24). However, large numbers of studies have been carried out and results are variable with some authors indicating evidence for the effect of uncharacterized superantigens expanding or deleting $\mathrm{T}$ cells with particular $\mathrm{V}$ beta regions. While, others have suggested that observations of restricted $V$ region usage and limited junctional regions imply that clones of cells have been expanded by antigen (25). An experimental study results revealed that proliferation and interleukin-2 (IL-2) production was dependent on the dose and type of staphylococcal enterotoxins (SEs) (26).

To investigate the role of superantigen in rheumatoid arthritis (RA), serum IgG and IgM SEB antibodies were measured using an enzyme linked immunosorbent assay (ELISA), and confirmed by Western blot analysis. The results indicate that patients with RA have increased levels of serum IgM SEB antibody compared to normal subjects. In this study, the titers of rheumatoid factor (RF) showed no correlation with the levels of IgM SEB antibodies (27). The results of another study suggest that superantigens are implicated in the pathogenesis of certain autoimmune diseases such as multiple sclerosis, RA, Sjogren's syndrome, and Kawasaki's syndrome (28).

The results of a study showed that superantigen stimulated mononuclear cells from the synovial fluid of patients with RA with higher levels of TNF- $\alpha$ production (29). By using Fas-defective MRL-lpr/lpr mice, the effects of the staphylococcal enterotoxin B (superantigen) were studied on the development of autoimmune, inflammatory joint disease in susceptible animals to the development of rheumatoid arthritis-like disease and showed that a single intraperitoneal injection of staphylococcal enterotoxin B (SEB; $10 \mu \mathrm{g} /$ mouse) caused a mild, inflammatory arthritis plus 30 days post challenge in the knee joints of young (<2-month-old) MRL-lpr/lpr mice. They concluded that SEB is an extremely potent macrophage-activating factor both in vitro and in vivo, enhancing several aspects of autoimmune disease in MRL-lpr/lpr mice (30).

In an investigation, the effects of the superantigens staphylococcal enterotoxin A, staphylococcal enterotoxin $\mathrm{B}$, and streptococcal $\mathrm{M}$ type 5 protein on $\mathrm{T}$ cells derived from inflammatory tissues and peripheral blood (PB) of patients with arthritis were studied and demonstrated the heterogeneities of such superantigen-mediated specific cell lysis (31). Another investigation showed that superantigen toxic shock syndrome toxin-1(TSST-1) stimulated T cells from Rheumatoid arthritis synovial fluid mononuclear cells (RASFMC) have the ability to induce chronic arthropa- 
thy with fibroblast proliferation and neovascularization in the severe combined immunodeficient (SCID) mouse (32). The selected elevation of antibodies to MAM in RA sera was subjected to study and showed that MAM or a MAM-like molecule might be associated with RA, whereas elevation of antibodies to SEA and SEB in sera from patients with rheumatic diseases was less specific (33).

The prevalence of S. aureus nasal carriage and comparing antibody responses to two superantigens, staphylococcal toxic shock syndrome toxin-1 (TSST-1) and staphylococcal enterotoxin A (SEA), in patients with RA and normal subjects were studied and revealed that, patients with RA more often carry S. aureus in their nasal vestibule, and have higher average antibody levels to TSST-1 (34). Previous reports showed that streptococcal IgG Fc receptors and RFs bind to the same amino acids on the Fc molecule. This complex pattern may play a role in the pathogenesis of RA (35). In addition, the possibility that IgM rheumatoid factors bind to streptococci was studied (36). In an experimental study by subcutaneous injection of staphylococcal enterotoxin B (SEB), severe arthritis was induced in DBA/1J mice, which had been previously immunized with bovine type II collagen and suggested that this experimental arthritis model may provide a means to examine the role of superantigens and the efficacy of pharmacological agents for the treatment of rheumatoid arthritis (37).

The prevalence of oral staphylococcal carriage in patients with RA compared with healthy controls was carried out and showed that oral carriage of $S$. aureus appears to be common in patients with RA and studies of the mouth as a source of infection in septic arthritis would be merited (38). It is reported that in early stages of untreated RA, simultaneous IL-17assessment of serum, SF, and synovium might be valuable in defining activity and predictive patterns of RA, given that synovium is highly suggestive for disease aggressiveness and might express specific therapeutically targets (39). So far, there is no reports indicative of the direct identification of an antigen or superantigen in blood or synovial fluid of patients, which plays a role in RA pathogenesis.

In this study, a total of 83 blood samples from patients with RA have been assayed for the presence of S. aureus enterotoxin E using bacterial culture, ELISA, and PCR methods. The result of bacterial culture showed that there were only two isolated bacteria as Gram-positive (S. aureus and S. intermedius). The results of ELISA test on extracted of overnight isolated culture showed no existence of enterotoxin $\mathrm{E}$ in all bacterial isolated cases. In addition, DNA extraction and PCR method for the presence of enterotoxin $\mathrm{E}$ gene for all bacterial isolates were negative. In fact, enterotoxin $\mathrm{E}$ or other proteins in culture extracts of isolated bacteria that could react with antienterotoxin E antibody in ELISA test have not been found.

While, the result of ELISA and PCR assessments of 79 blood buffy coat indicated the presence of enterotoxin $E$ in 34 cases (40.96\%) and the presence of enterotoxin $E$ gene in 11 cases (13.25\%). The interpretation of these results is difficult. Because first of all, S. aureus produces more than 20 types of enterotoxins and there is a great similarity among them. Secondly, in spite of their different structural features, they have similar mechanism of action. Meanwhile, this study aimed at detection of only one enterotoxin. It is noteworthy that, the PCR and ELISA results were the same only in 10 cases. In one case, the PCR result for the presence of enterotoxin E gene was positive. While ELISA results for the existence of enterotoxin E were negative. The reason is probably the lack of gene expression or inadequate production of enterotoxin that was under of ELISA sensitivity.

The important finding of this study was that most of the samples -in 24 cases- showed positive ELISA results. Whereas, negative results for PCR was obtained. PCR has been repeated by the different Genomic DNA Extraction Kit that referred to the differences between PCR and ELISA results have been decreased, albeit not completely. Perhaps the difference is due to the similarities between enterotoxin E with other enterotoxins such as enterotoxins A and P. However, the results of this study indicate that the PCR molecular method and ELISA can detect enterotoxin $\mathrm{E}$ in the blood of patients with RA. The results have created an important question. Why has the toxin been found in the patient's blood, while the bacterial growth in blood cultures is negative? To provide answers to this question, further research is needed. In addition, there is another important question. Why is still the role of staphylococcal enterotoxins as superantigens in inflammation and RA discussed? However, there has been no attempt reported so far for detection of these enterotoxins in patient's blood. Perhaps one reason is the inability of the different tests. In our previous study, by using commercial ELISA kit, enterotoxin A, B, C, D, and E had been detected in synovial fluid of patients (17), and confirmed by immunoblotting. Thus in the present study, in order to determine the staphylococcal enterotoxin E, we focused on enterotoxin E recognition by ELISA and PCR in patient's blood with RA. However, not only the results of this study have shown some evidence regarding endogenous origin for involved superantigens in patients with RA but also could provide a good model for the diagnosis of RA etiology. However, owning to the fact that there are no similar studies for comparison and analyses of the results, more research with a larger sample size is recommended.

\section{Acknowledgements}

The authors would like to thank the head of Baqiyatallah Research Institute, Professor Mostafa Ghanei and the head of Molecular Research Center Dr Reza Ranjbar, as well as Dr Mehdi Bahari Mehrabani and Dr Shadmanfar who helped us for collecting patient's blood samples.

\section{Authors' Contributions}

Ramezan Ali Ataee developed the original idea and 
the protocol. Gholam Hossein Alishiri selected and introduced the patients. Ramezan Ali Ataee and Samaneh Zahiri Yeganeh designed the experimental protocols, abstracted the data, and prepared the manuscript. Monireh Movahedi was Biochemical Consulter of this research and read the final version.

\section{Funding/Support}

This project was partially supported by Baqiyatallah University of Medical Sciences.

\section{References}

1. Jekle A, Yoon J, Zuck M, Najafi R, Wang L, Shiau T, et al. NVC-422 inactivates Staphylococcus aureus toxins. Antimicrob Agents Chemother. 2013;57(2):924-9.

2. Danielsen EM, Hansen GH, Karlsdottir E. Staphylococcus aureus enterotoxins $\mathrm{A}$ - and $\mathrm{B}$ : binding to the enterocyte brush border and uptake by perturbation of the apical endocytic membrane traffic. Histochem Cell Biol. 2013;139(4):513-24.

3. Sospedra I, Soler C, Manes J, Soriano JM. Rapid whole protein quantitation of staphylococcal enterotoxins A and B by liquid chromatography/mass spectrometry. J Chromatogr A. 2012;1238:54-9.

4. Gevaert P, Nouri-Aria KT, Wu H, Harper CE, Takhar P, Fear DJ, et al. Local receptor revision and class switching to IgE in chronic rhinosinusitis with nasal polyps. Allergy. 2013;68(1):55-63.

5. Schlievert PM, Case LC. Molecular analysis of staphylococcal superantigens. Methods Mol Biol. 2007;391:113-26.

6. Kanangat S, Postlethwaite A, Hasty K, Kang A, Smeltzer M, Appling $\mathrm{W}$, et al. Induction of multiple matrix metalloproteinases in human dermal and synovial fibroblasts by Staphylococcus aureus: implications in the pathogenesis of septic arthritis and other soft tissue infections. Arthritis Res Ther. 2006;8(6):R176.

7. Sina H, Ahoyo TA, Moussaoui W, Keller D, Bankole HS, Barogui Y et al.Variability of antibiotic susceptibility and toxin production of Staphylococcus aureus strains isolated from skin, soft tissue, and bone related infections. BMC Microbiol. 2013;13:188.

8. Ostyn A, De Buyser ML, Guillier F, Groult J, Felix B, Salah S, et al First evidence of a food poisoning outbreak due to staphylococcal enterotoxin type E, France, 2009. Euro Surveill. 2010;15(13).

9. Derzelle S, Dilasser F, Duquenne M, Deperrois V. Differential temporal expression of the staphylococcal enterotoxins genes during cell growth. Food Microbiol. 2009;26(8):896-904.

10. Couch JL, Soltis MT, Betley MJ. Cloning and nucleotide sequence of the type E staphylococcal enterotoxin gene. J Bacteriol. 1988;170(7):2954-60.

11. Wang WY, Lee S, Chiueh T, Lu JJ. Molecular and phenotypic characteristics of methicillin-resistant and vancomycin-intermediate Staphylococcus aureus isolates from patients with septic arthritis. J clin microbiol. 2009;47(11):3617-23.

12. Lattar SM, Tuchscherr LP, Centron D, Becker K, Predari SC, Buzzola FR, et al. Molecular fingerprinting of Staphylococcus aureus isolated from patients with osteomyelitis in Argentina and clonal distribution of the cap5(8) genes and of other selected virulence genes. Eur J Clin Microbiol Infect Dis. 2012;31(10):2559-66.

13. Barretti P, Montelli AC, Batalha JE, Caramori JC, Cunha Mde L. The role of virulence factors in the outcome of staphylococcal peritonitis in CAPD patients. BMC Infect Dis. 2009;9:212.

14. Ataee R, Esmaeili D, Khanshan R. . Heterologous Expression of Staphylococcal Enterotoxin E Gene. J pure appli microbiol. 2013;7(2):957-63.

15. Aletaha D, Neogi T, Silman AJ, Funovits J, Felson DT, Bingham CO 3rd, et al. 2010 Rheumatoid arthritis classification criteria: an American College of Rheumatology/European League Against Rheumatism collaborative initiative. Arthritis Rheum. 2010;62(9):2569-81.

16. Sambrook J, Russel DW. Molecular Cloning. 3 edNew York: Cold- spring Harbour Laboratory Press; 2001.

17. Ataee RA, Mohoseni-Moghadam Z, Salimzadeh A, Latifi AM, Ataee $\mathrm{MH}$, Alishiri GH. Enzyme-linked Immunosorbent Assay for Detection of Staphylococcal Enterotoxins in Synovial Fluid of Rheumatoid Arthritis Pateints. J Pure Appl Microbiol. 2013;7(2):1113-9.

18. Sioud M, Kjeldsen-Kragh J, Suleyman S, Vinje O, Natvig JB, Forre $\mathrm{O}$. Limited heterogeneity of $\mathrm{T}$ cell receptor variable region gene usage in juvenile rheumatoid arthritis synovial T cells. Eur J Immunol.1992;22(9):2413-8.

19. Zangerle PF, De Groote D, Lopez M, Meuleman RJ, Vrindts Y, Fauchet F, et al. Direct stimulation of cytokines (IL-1 beta, TNFalpha, IL-6, IL-2, IFN-gamma and GM-CSF) in whole blood: II. Application to rheumatoid arthritis and osteoarthritis. Cytokine. 1992;4(6):568-75.

20. Schwab JH, Brown RR, Anderle SK, Schlievert PM. Superantigen can reactivate bacterial cell wall-induced arthritis. J Immunol. 1993;150(9):4151-9.

21. al-Daccak R, Mehindate K, Hebert J, Rink L, Mecheri S, Mourad W. Mycoplasma arthritidis-derived superantigen induces proinflammatory monokine gene expression in the THP-1 human monocytic cell line. Infect Immun. 1994;62(6):2409-16.

22. Rink L, Nicklas W, Luhm J, Kruse R, Kirchner H. Induction of a proinflammatory cytokine network by Mycoplasma arthritidis-derived superantigen (MAS). J Interferon Cytokine Res. 1996;16(10):861-8.

23. He X, Zhong W, McCarthy TG, Weyand CM, Goronzy JJ. Increased responsiveness of rheumatoid factor-producing B cells in seronegative and seropositive rheumatoid arthritis. Arthritis Rheum. 1996;39(9):1499-506.

24. Origuchi T, Eguchi K, Kawabe Y, Mizokami A, Ida H, Nagataki S. Synovial cells are potent antigen-presenting cells for superantigen, staphylococcal enterotoxin B (SEB). Clin Exp Immunol. 1995;99(3):345-51.

25. Lanchbury JS, Hall MA. T cell receptor usage in rheumatoid arthritis. Br Med Bull.1995;51(2):346-58.

26. Kraft M, Filsinger S, Kramer KL, Kabelitz D, Hansch GM, Schoels M Synovial fibroblasts as accessory cells for staphylococcal enterotoxin-mediated T-cell activation. Immunology. 1995;85(3):461-6.

27. Origuchi T, Eguchi K, Kawabe Y, Yamashita I, Mizokami A, Ida H, et al. Increased levels of serum IgM antibody to staphylococcal enterotoxin B in patients with rheumatoid arthritis. Ann Rheum Dis. 1995;54(9):713-20.

28. Meyer O. [Superantigens and their implication in autoimmune diseases]. Presse Med.1995;24(25):1171-7.

29. Akatsuka H, Okubo M, Ishida H, Chiba K, Imanishi K, Uchiyama $\mathrm{T}$, et al. Synovial mononuclear cells consist with $\mathrm{T}$ cells which produce high levels of tumor necrosis factor alpha. Microbiol Immunol.1997;41(4):367-70.

30. Edwards CK 3rd, Zhou T, Zhang J, Baker TJ, De M, Long RE, et al Inhibition of superantigen-induced proinflammatory cytokine production and inflammatory arthritis in MRL-lpr/lpr mice by a transcriptional inhibitor of TNF-alpha. J Immunol. 1996;157(4):1758-72.

31. Li S, Quayle AJ, Thoen JE, Forre OT. Superantigen-mediated proliferation and cytotoxicity of T cells isolated from the inflammatory tissues and peripheral blood of arthritis patients. Clin Immunol Immunopathol.1996;79(3):278-87.

32. Suzuki T, Nishimaki T, Kogure A, Okubo M, Akatsuka H, Kokubun $\mathrm{M}$, et al. Synoviocyte proliferation in joints of SCID mice induced by toxic shock syndrome toxin- 1 stimulated T cells from patient with rheumatoid arthritis. J Rheumatol.1997;24(6):1115-21.

33. Sawitzke A, Joyner D, Knudtson K, Mu HH, Cole B. Anti-MAM antibodies in rheumatic disease: evidence for a MAM-like superantigen in rheumatoid arthritis? J Rheumatol. 2000;27(2):358-64.

34. Tabarya D, Hoffman WL. Staphylococcus aureus nasal carriage in rheumatoid arthritis: antibody response to toxic shock syndrome toxin-1. Ann Rheum Dis. 1996;55(11):823-8.

35. Schroder AK, Gharavi AE, Christensen P. Molecular interactions between human IgG, IgM rheumatoid factor and streptococcal IgG Fc receptors. Int Arch Allergy Appl Immunol. 1988;86(1):92-6.

36. Schroder AK, Christensen P, Svensson ML. Binding of IgM rheumatoid factor to group A, C and G streptococci with IgG Fc recep- 


\section{Zahiri Yeganeh S et al.}

tors. Int Arch Allergy Appl Immunol.1986;80(1):52-6.

37. Nagai H, Takaoka Y, Kamada H, Mori H. The model of arthritis induced by superantigen in mice. Life Sci. 1994;55(12):PL233-7.

38. Jackson MS, Bagg J, Gupta MN, Sturrock RD. Oral carriage of staphylococci in patients with rheumatoid arthritis. Rheumatol- ogy (Oxford). 1999;38(6):572-5.

39. Rosu A, Margaritescu C, Stepan A, Musetescu A, Ene M. IL-17 patterns in synovium, serum and synovial fluid from treatment-naive, early rheumatoid arthritis patients. Rom J Morphol Embryol. 2012;53(1):73-80. 